\title{
Intra-abdominal hypertension; prevalence, incidence and outcomes in a low resource setting; a prospective observational study
}

Job Kuteesa ${ }^{1,4^{*}}$, Olivia Kituuka ${ }^{1}$ Dan Namuguzi ${ }^{1}$, Cynthia Ndikuno², Samuel Kirunda', David Mukunya ${ }^{3}$ and Moses Galukande ${ }^{1}$

\begin{abstract}
Background: Intra-abdominal hypertension (IAH) is defined as a sustained elevation in intra-abdominal pressure (IAP) greater than or equal to $12 \mathrm{mmHg}$. IAH has been shown to cause organ derangements and dysfunction in the body. Objective screening of IAH is neither done early enough nor at all thus leading to significant morbidity and mortality among surgical patients. The epidemiology and outcome of IAH among surgical patients has not been documented in Uganda. The aim of this study was to determine the prevalence, incidence and outcome of intra-abdominal hypertension among patients undergoing emergency laparotomy.
\end{abstract}

Methodology: Prospective observational study, conducted from January to April 2015 among patients undergoing emergency laparotomy. Inclusion criteria was; age $>7$ yrs, scheduled for emergency laparotomy, able to lie supine. Exclusion Criteria: pregnant, failed urethral catheterization, known cardiac, renal and respiratory disorders. Consecutive sampling was used. IAP, blood pressure, heart rate, respiratory rate, Sp02, Serum creatinine, Serum urea, and Urine output were measured preoperatively and postoperatively at 0, 6, 24 and $48 \mathrm{~h}$. IAH was defined as IAP > $12 \mathrm{mmHg}$ on three consecutive readings $3 \mathrm{~min}$ apart.

Results: In total 192 patients were enrolled. Mean age \pm SD was $14.25( \pm 3.16)$ yrs in the paediatrics and $34.4( \pm 13.72)$ yrs in the adults with male preponderance 65 and $80.7 \%$ respectively. The prevalence of IAH was $25 \%$ paediatrics and $17.4 \%$ adults and the cumulative incidence after surgery was $20 \%$ paediatrics and $21 \%$ adults. In paediatrics, IAH was associated with mortality at $0 \mathrm{~h}$ postoperatively, RRR $=1: 24,95 \% \mathrm{Cl}(1.371-560.178), p$-value 0.048 . In adults, the statistically significant outcomes associated with IAH were respiratory system dysfunction RRR1:2.783, $p$-value $0.023,95 \% \mathrm{Cl}(1.148-6.744)$ preoperatively and mortality RRR 1:2.933, $p$-value $0.034,95 \% \mathrm{Cl}(1.017-8.464)$ at $6 \mathrm{~h}$, RRR 1:3.769, $p$-value $0.033,95 \% \mathrm{Cl}(1.113-12.760)$ at $24 \mathrm{~h}$ postoperatively.

Conclusion: The prevalence and incidence of IAH in the paediatrics and adults group in our study population were high. IAH was associated with mortality in both adult and paediatrics groups and respiratory system dysfunction in adult group. This calls for objective monitoring of intraabdominal pressure in patients undergoing emergency laparotomy with the aim of reducing associated mortality.

Keywords: Intra-abdominal pressure, Intra-abdominal hypertension, Emergency laparotomy, Mortality

\footnotetext{
* Correspondence: kuteesajob@gmail.com

${ }^{1}$ Department of Surgery, College of Health Sciences, Makerere University,

Mulago Hill road, P.O Box 7072, Kampala, Uganda, East Africa

${ }^{4}$ Department of Surgery, School of Medicine, College of Health Sciences,

Makerere University, P.O Box 7072 Kampala, Uganda

Full list of author information is available at the end of the article
}

C Biomed Central (c) 2015 Kuteesa et al. Open Access This article is distributed under the terms of the Creative Commons Attribution 4.0 International License (http://creativecommons.org/licenses/by/4.0/), which permits unrestricted use, distribution, and reproduction in any medium, provided you give appropriate credit to the original author(s) and the source, provide a link to the Creative Commons license, and indicate if changes were made. The Creative Commons Public Domain Dedication waiver (http://creativecommons.org/publicdomain/zero/1.0/) applies to the data made available in this article, unless otherwise stated. 


\section{Background}

Intra-abdominal hypertension is a sustained or repeated elevation in Intra-Abdominal pressure (IAP) greater than or equal to $12 \mathrm{mmHg}$ [1]. IAP is the steady-state pressure concealed within the abdominal cavity [1]. It's usually increased in abdominal surgical emergencies. This increased IAP leads to significant organ dysfunction; respiratory, cardiac, renal, gastrointestinal which inevitably leads to increase morbidity and mortality [2-5].

The elevated Intra abdominal pressure leads to a splinting effect on the diaphragm resulting in reduction in lung and chest wall compliance hence the respiratory dysfunction [6, 7]. When the IAP is $\geq 15 \mathrm{mmHg}$; there is impairment of venous return from the inferior vena cava. At about $\geq 20 \mathrm{mmHg}$, there is substantial collapse of abdominal veins (mesenteric, renal and inferior venacava, etc.) hence the significant drop in venous return and this will lead to reduced cardiac output [7-9]. The second effect on the heart is the elevated after load due to increased systemic vascular resistance mainly from the high intra-abdominal pressure and increased intrathoracic pressure [8]. The reduced after load in addition to the venous compression will in turn affect the central nervous system, renal and gastrointestinal system through ischaemia [7, 9].

Despite the growing awareness of the IAH and its adverse consequences; this has coincided with a significant increase in the number of publications related to the theme, many clinicians are not able to recognise or diagnose it early $[10,11]$ and it's currently not a routine practice to measure IAP in Uganda.

Therefore in this study we aimed to determine the prevalence, incidence and outcome of IAH among patients undergoing emergency laparotomy.

\section{Methods}

Study design

A prospective observational study.

\section{Study setting}

This study was conducted in the surgery department of Mulago National Referral Hospital (MNRH), Kampala district. MNRH is Uganda's national referral hospital. It is also the teaching hospital for the Makerere University College of Health Sciences. It has a total bed capacity of 1500 , an inpatient turnover of 120,000 patients and attends to over 480,000 outpatients annually. The study was conducted between January and April 2015. Patients were followed up until discharge or death.

\section{Participants}

All patients above $7 \mathrm{yr}$ that were scheduled for emergency laparotomy in the surgery department of MNRH were eligible for the study provided they were not pregnant, urinary catheterization was possible and did not have any of the following; pelvic fractures, haematuria, neurogenic bladder, cardiac, renal or respiratory conditions.

\section{Study procedure, measurements and sample collection procedure}

A patient was included in the study only after a decision to operate upon him/her was taken by the attending surgical team. Patient particulars (age, sex, tribe, weight, height, past medical history) were noted along with the diagnosis and indication for surgery. Measurement of IAP was taken three times on each occasion and the average was recorded. The measurements were done in the preoperative period and then postoperatively at 0,6 , 24 and $48 \mathrm{~h}$. Zero hour was taken as time of up to $3 \mathrm{~h}$ after surgery. If IAP remained below $12 \mathrm{mmHg}$, measurements were discontinued after $24 \mathrm{~h}$. Other parameters were measured preoperatively and then after surgery at 0, 6, 24 and $48 \mathrm{~h}$. These included; blood pressure, pulse rate, respiratory rate, oxygen saturation (SpO2), temperature, urine output, Glasgow coma score, duration of surgery, blood urea, serum creatinine. Zero hour was taken as time of up to $3 \mathrm{~h}$ after surgery.

Post-operational findings to note include: duration of hospital stay, morbidity (burst abdomen), and mortality. The patients were followed up until discharge for morbidity (burst abdomen, relaparotomy, wound dehiscence and wound sepsis) and mortality.

\section{Details of the measurement of the IAP}

The patient was placed in supine position and catheterized with a Foley's catheter. The bladder was drained until no urine was flowing out from the catheter. The Unometer (UnoMeter ${ }^{\mathrm{TM}}$ Abdo-Pressure ${ }^{\mathrm{TM}}$ manufactured Unomedical, Uno label 005-2) was connected to the Foley's Catheter then $20 \mathrm{mls}$ (10-20 mls in Paediatrics) of sterile saline was infused into the bladder through an opening on the Unometer (as recommended by the manufacturer of the Unometer). The tubing of the collecting bag was clamped. The symphysis pubis was the point of zero reference. The patient was told to expire and hold their breath, in that moment the pressure was measured in millimeters of mercury. The measurement was repeated three times with a gap of about $3 \mathrm{~min}$ between the readings.

\section{Study variables Independent variables}

Patient's age (in complete years), gender, weight (in kilograms), height (in meters), diagnosis, duration of surgery (in minutes). 


\section{Dependent variables}

Renal dysfunction(creatinine, urea and urine output), respiratory dysfunction(Respiratory rate, $\mathrm{SpO}_{2}$, cardiovascular dysfunction(MAP, Heart rate), central nervous system dysfunction(GCS), intra-abdominal pressure duration of hospital stay, morbidity (burst abdomen, relaparotomy, wound dehiscence and wound sepsis), and mortality.

\section{Interpretation of findings}

Grading of intra-abdominal hypertension for adults

1. Grade I: $12-15 \mathrm{mmHg}$;

2. Grade II: $16-20 \mathrm{mmHg}$;

3. Grade III: $21-25 \mathrm{mmHg}$; and

4. Grade IV: $>25 \mathrm{~mm} \mathrm{Hg}$

Grading of intra-abdominal hypertension for paediatrics

1. Grade I: $10-12 \mathrm{mmHg}$,

2. Grade II: $13-15 \mathrm{mmHg}$,

3. Grade III: $16-19 \mathrm{mmHg}$; and

4. Grade IV: $\geq 20 \mathrm{mmHg}$

Patients (adults) were considered to have ACS when they had IAH > $25 \mathrm{mmHg}$ with evidence of a newly developed organ dysfunction. In Paediatric group, ACS was sustained IAP of greater than $10 \mathrm{mmHg}$ associated with new organ dysfunction/failure. Intervention was left for the attending surgeon to decide.

\section{Organ system derangement}

Cardiovascular system

1. $\mathrm{MAP}<60 \mathrm{mmHg}$

2. Heart rate $>100 / \mathrm{min}$

3. Both of the above

Respiratory system

1. Respiratory rate $>20 / \mathrm{min}$ or

2. $\mathrm{SpO} 2<90 \%$ or

3. Patient in need of ventilatory support or

4. Any two or all of the above

Renal system

1. Serum creatinine $>106 \mathrm{umol} / \mathrm{L}$ or

2. Blood urea $>6.4 \mathrm{umol} / \mathrm{L}$ or

3. Urine output $<25 \mathrm{ml} / \mathrm{h}$ or

4. Any two or all of the above

Central nervous system
Glasgow Coma Scale: 15-14; Mild, 13-9; Moderate, $<8$; Severe.

Below 14//15, was be considered as CNS dysfunction

\section{Study size}

The sample size for prevalence and incidence was calculated using the modified Keish and Leslie formula using an estimated proportion of $50.5 \%$, from a multicentre epidemiological study [12], and a precision of 0.05 . The estimated sample size for comparing IAH and outcomes was derived from a general formula for calculating the total sample size using the $\mathrm{z}$ statistic for comparison of two proportions with an estimated proportion of $80 \%$ from an Indian study [13]. The larger sample size of 141 patients was considered.

\section{Statistical methods \\ Data entry}

Data was double entered into Epi Data version 3.1 with range, consistency and validity checks embedded to ensure accuracy of data. The data was stored on a computer hard drive that is password protected to ensure confidentiality and backed up on separate external hard drives kept in separate locations.

\section{Data analysis}

Univariate analysis was performed for baseline factors of the study. For continuous variables such as age; means (standard deviations) and median (interquartile range) if data was skewed, were reported. For categorical variables, proportions and percentages were reported and findings displayed in frequency distribution tables.

Multivariate analysis using the multinomial logistic regression at $95 \%$ confidence interval and $P$-value $<0.05$ statistical significance, organ dysfunction, morbidity rate, mortality rate were considered as outcomes of IAH. Results were reported in relative risk ratios and $p$-value.

\section{Quality control}

The recruited research assistants were trained on the use of the data collection tool, how to do the different measurements and patient approach. The data collection tool was pretested. We cross-checked the data daily to ensure completeness with double data entry. An accurate history and physical examination of the patients was done.

Measurements of the IAP were done three times $3 \mathrm{~min}$ apart and the average was recorded and to increase accuracy. Standardized machines were used to measure other parameters such as SpO2, MAP, and PR etc.

Data cleaning and entry was done occasionally. There was periodic data evaluation. All questionnaires were safely stored to enable reference in case of data loss. 


\section{Ethical consideration}

Informed written consent was obtained from the participants; a translated consent form was availed to nonEnglish speaking respondents. Accent was obtained from the children and written informed consent from the guardian. Confidentiality was observed through strict storage of data and no use of names. Ethical Approval was obtained from; Mulago Hospital ethics committee, Makerere University school of medicine ethics and research committee and the Uganda National council science and technology.

\section{Results}

\section{Characteristics of the study participants}

A total of 192 patients were enrolled in this study. Of these, in the paediatric group $13(65.5 \%)$ patients and in adult group 138 (80.7 \%) were male. Patients' age ranged from 9-86 years, paediatrics (9-18) years and adults (19-86) years. The paediatric mean age was 14.25 years $(\mathrm{SD} \pm 3.16)$ and adult age was $34.4 \mathrm{yrs}(\mathrm{SD} \pm 13.72)$. The paediatric age median was 15 years and adult median 30 years (See Table 1 ).

\section{Intra-abdominal hypertension}

IAH was reported as No IAH for values $(<10 \mathrm{mmHg})$ paediatrics, $(<12 \mathrm{mmHg})$ adult or IAH for values $(\geq 10 \mathrm{mmHg})$ paediatrics and $(\geq 12 \mathrm{mmHg}$ ) adults. Table 2 shows the different percentages of the patients who presented with or developed IAH and those who did not develop IAH both preoperatively and postoperatively.

\section{Prevalence and incidence of $\mathrm{IAH}$}

The prevalence of IAH in this study was $25 \%$ paediatrics and $17.4 \%$ adults. Overall incidence of IAH was $20 \%$ paediatrics and $21 \%$ adults. The incidence of IAH at $0,6,24$ and $48 \mathrm{~h}$ is presented in the Table 2 .

\section{Outcomes associated with IAH among patients scheduled for emergency laparotomy}

Multivariate analysis was carried out using the multinomial logistic regression in order to determine the significant outcome factors for IAH. Tables 3, 4, 5, and 6 below show IAH as a predictor of the outcomes of organ dysfunction (respiratory and renal), morbidity and mortality in paediatrics and adults groups.

In the paediatrics group, Patients with IAH postoperatively at $6 \mathrm{~h}$ were more than twenty four times at risk of dying as compared to those without IAH, RRR $=1: 24,95 \%$ CI (1.371-560.178), $p$-value 0.048 .

In the adults group, patients with IAH preoperatively were 2.7 times more likely to develop respiratory dysfunction compared to those without IAH, RRR $=1: 2.783$, $95 \%$ CI (1.148-6.744), and p-value 0.023.
Table 1 A table showing descriptive characteristics of the study participants

\begin{tabular}{|c|c|c|c|c|}
\hline \multirow[t]{2}{*}{ Characteristic } & \multicolumn{2}{|l|}{ Paediatric } & \multicolumn{2}{|l|}{ Adults } \\
\hline & $\begin{array}{l}\text { Frequency } \\
(N=20)\end{array}$ & $\begin{array}{l}\text { Proportion } \\
(\%)\end{array}$ & $\begin{array}{l}\text { Frequency } \\
(N=172)\end{array}$ & $\begin{array}{l}\text { Proportion } \\
(\%)\end{array}$ \\
\hline \multicolumn{5}{|l|}{ Age } \\
\hline Mean (SD) & \multicolumn{2}{|l|}{$14.25( \pm 3.16)$} & \multicolumn{2}{|l|}{$34.46( \pm 13.72)$} \\
\hline Median & \multicolumn{2}{|l|}{15.0} & \multicolumn{2}{|l|}{30.0} \\
\hline \multicolumn{5}{|l|}{ Gender } \\
\hline Male & 13 & 65.5 & 138 & 80.7 \\
\hline \multicolumn{5}{|l|}{ BMI } \\
\hline $\begin{array}{l}\text { Underweight } \\
(<18.5)\end{array}$ & 10 & 50.0 & 14 & 8.1 \\
\hline $\begin{array}{l}\text { Normal weight } \\
(18.5-24.9)\end{array}$ & 10 & 50.0 & 132 & 76.7 \\
\hline $\begin{array}{l}\text { Overweight } \\
(25.0-29.9)\end{array}$ & - & 0.0 & 14 & 8.1 \\
\hline $\begin{array}{l}\text { Class I obesity } \\
(30.0-34.9)\end{array}$ & - & 0.0 & 5 & 2.9 \\
\hline $\begin{array}{l}\text { Class II obesity } \\
(35.0-39.9)\end{array}$ & - & 0.0 & 2 & 1.2 \\
\hline \multicolumn{5}{|l|}{ Referral } \\
\hline Yes & 12 & 60.0 & 93 & 54.4 \\
\hline \multicolumn{5}{|l|}{$\begin{array}{l}\text { Indication for } \\
\text { emergency } \\
\text { laparotomy }\end{array}$} \\
\hline $\begin{array}{l}\text { Intra- } \\
\text { abdominal } \\
\text { sepsis }\end{array}$ & 14 & 70.0 & 113 & 66.1 \\
\hline $\begin{array}{l}\text { Intestinal } \\
\text { obstruction }\end{array}$ & 5 & 25.0 & 11 & 6.4 \\
\hline Trauma & 1 & 5.0 & 43 & 25.1 \\
\hline Others $^{1}$ & 0 & 0.0 & 4 & 2.3 \\
\hline \multicolumn{5}{|l|}{$\begin{array}{l}\text { Operative } \\
\text { findings }\end{array}$} \\
\hline Trauma related & 4 & 20.0 & 10 & 5.8 \\
\hline $\begin{array}{l}\text { Non trauma } \\
\text { relate }\end{array}$ & 15 & 75.0 & 144 & 84.2 \\
\hline \multicolumn{5}{|l|}{$\begin{array}{l}\text { Duration of } \\
\text { surgery }\end{array}$} \\
\hline$<60 \min$ & 4 & 20 & 48 & 27.9 \\
\hline $\begin{array}{l}60 \text { min- } \\
<90 \text { min }\end{array}$ & 9 & 45.0 & 50 & 29.1 \\
\hline $\begin{array}{l}90 \text { min- } \\
<2 \text { hours }\end{array}$ & 6 & 30.0 & 40 & 23.3 \\
\hline$>2$ hours & 0 & 0.0 & 15 & 8.7 \\
\hline \multicolumn{5}{|l|}{ Morbidity } \\
\hline Present & 4 & 20.0 & 42 & 24.4 \\
\hline \multicolumn{5}{|l|}{ Mortality } \\
\hline $\begin{array}{l}\text { Death } \\
\text { occurred }\end{array}$ & 4 & 20.0 & 42 & 24.4 \\
\hline
\end{tabular}

Paediatric $\mathrm{IAH} \geq 10 \mathrm{mmHg}$ and Adult $\mathrm{IAH} \geq 12 \mathrm{mmHg}$ 
Table 2 ATable showing prevalence and incidence of IAH before and after emergency laparotomy

\begin{tabular}{|c|c|c|c|c|}
\hline \multirow[t]{2}{*}{ Characteristic } & \multicolumn{2}{|l|}{ Paediatric } & \multicolumn{2}{|l|}{ Adults } \\
\hline & Frequency $(n=20)$ & Proportion (\%) & Frequency $(n=172)$ & Proportion (\%) \\
\hline \multicolumn{5}{|l|}{ Preoperative } \\
\hline No IAH & 13 & 65.0 & 134 & 77.9 \\
\hline $\mathrm{IAH}$ & 5 & 25.0 & 30 & 17.4 \\
\hline \multicolumn{5}{|c|}{ Overall Postoperative } \\
\hline No IAH & 15 & 75.0 & 110 & 63.9 \\
\hline $\mathrm{IAH}$ & 4 & 20.0 & 37 & 21.5 \\
\hline \multicolumn{5}{|c|}{ IAH at 0 hours $(n=153)$} \\
\hline No & 14 & 70.0 & 122 & 70.9 \\
\hline Yes & 3 & 15.0 & 14 & 8.1 \\
\hline \multicolumn{5}{|c|}{ IAH at 6 hours $(n=148)$} \\
\hline No & 18 & 90.0 & 108 & 62.8 \\
\hline Yes & 0 & 0.0 & 22 & 12.8 \\
\hline \multicolumn{5}{|c|}{ IAH at 24 hours $(n=148)$} \\
\hline No & 15 & 75.0 & 117 & 68.1 \\
\hline Yes & 1 & 5.0 & 15 & 8.7 \\
\hline \multicolumn{5}{|c|}{ IAH at 48 hours $(n=83)$} \\
\hline No & 5 & 10.0 & 63 & 36.6 \\
\hline Yes & 0 & 0.0 & 15 & 8.7 \\
\hline
\end{tabular}

Patients with IAH postoperatively at $6 \mathrm{~h}$ and at $24 \mathrm{~h}$ were noted to be more than 2.933 and 3.769 times more likely to die than those without IAH, 95 \% CIs (1.017$8.464)(1.113-12.760)$ and $p$-values $0.047,0.033$ respectively

There was an increasing likelihood or risk of dying with increasing time (hrs) among patients postoperatively with IAH.

\section{Discussion}

This study was conducted to find out the epidemiology of IAH and the association of IAH with organ dysfunction, morbidity (e.g. burst abdomen, re-laparotomy) and mortality among surgical patients undergoing emergency laparotomy. We found the prevalence to be $25 \%$ paediatrics and $17.4 \%$ adults, and incidence to be $20 \%$ paediatrics and $21 \%$ adults. IAH is a significant predictor of mortality and respiratory dysfunction.

\section{Basic Characteristics of the study participants}

In both the paediatrics and adults groups, there was a male predominance that is $65 \%$ in paediatrics and $80.7 \%$ in adults; a similarity is seen in a number of studies. A study done in India had $76 \%$ males [13], a study in children $57 \%$ male [14], in USA two studies were done which reflected males $70 \%$ [15] and $72 \%$ [16]. The mean age in the paediatrics group was 14.25 years $(\mathrm{SD} \pm 3.16)$ and adult age was 34.4 yrs
$(\mathrm{SD} \pm 13.72)$. The median age for paediatric and adults group was 15 and 30 years respectively which is consistent with the Uganda population statistics which show that Uganda has a young population [17]. In this study, intra-abdominal sepsis had $66 \%$ of the study population, which is similar with findings from Khan et al. (2010) where $64 \%$ presented with intraabdominal sepsis.

\section{Intra-abdominal pressures}

The mean IAP before and after emergency laparotomy were 15.4 (SD \pm 3.6$) \mathrm{mmHg}$ and 14.21 (SD \pm 5.0) $\mathrm{mmHg}$, respectively. The mean IAP in the study group of Khan et al. before and after decompressions were 16.6 (SD \pm 9.4) $\mathrm{mmHg}$ and $10.3(\mathrm{SD} \pm 3.1) \mathrm{mmHg}$, respectively [13]. Meldrum et al. reported higher values of preoperative IAP, 27 ( $\mathrm{SD} \pm 2.3$ ) [15]. This can be explained by the observation that in our study, $66 \%$ of the patients had peritonitis secondary to gut perforation leading to elevated IAP which, after decompression and removal of liters of fluids and gas, returned to normal level immediately.

\section{Prevalence of IAH}

The prevalence of IAH in our study was $25 \%$ paediatrics and $17.4 \%$ adults. In the adults group, this was slightly lower than Murtaza et al. who showed a prevalence of $28 \%$ [18], however this can be 
Table 3 Multivariate analysis showing IAH as a predictor of respiratory dysfunction and renal dysfunction among adult patients scheduled and underwent emergency laparotomy

\begin{tabular}{llll}
\hline Variable & RRR & $95 \% \mathrm{Cl}$ & $P$-value \\
Respiratory dysfunction & & & \\
\hline IAH preoperative &
\end{tabular}

No IAH

$\begin{array}{llll}\mathrm{IAH} & 2.783 & 1.148-6.744 & \mathbf{0 . 0 2 3}\end{array}$

IAH Postoperative

No IAH
IAH
IAH POstop O hr

IAH Postop $0 \mathrm{hr}$

$\mathrm{NO}$ IAH
$\mathrm{IAH}$

IAH Postop 6 hrs

No IAH 1

IAH

$$
\mathrm{No} \text { IAH }
$$

$\mathrm{IAH}$

1

1.399

$0.661-2.962$

0.379

1

0.873

$0.285-2.669$

0.811

1

0.952

$0.379-2.396$

0.917

IAH Postop 48 hrs

No IAH
IAH
Renal Dysfunction
AH preoperative

No IAH

IAH Postoperative

$\mathrm{NO}$ IAH
IAH

IAH Postop $0 \mathrm{hr}$

$$
\text { No IAH }
$$$$
\mathrm{IAH}
$$

IAH Postop 6 hrs

$$
\text { No IAH }
$$$$
\mathrm{IAH}
$$

IAH Postop 24 hrs

No IAH 1

IAH

IAH Postop 48 hrs

\begin{tabular}{llll} 
No IAH & 1 & & \\
IAH & 0.331 & $0.068-1.606$ & 0.170 \\
\hline Highlighted variables statistically significant findings since $p$-value $<0.05$
\end{tabular}

Highlighted variables statistically significant findings since $p$-value $<0.05$

explained by the fact that Murtaza et al. looked at ICU patients who are generally sicker than the general patients we looked at. Again in the paediatrics group, the prevalence was lower compared to Ozden
Table 4 Multivariate analysis showing IAH as a predictor of respiratory dysfunction and renal dysfunction among Pediatric patients scheduled and underwent Emergency laparotomy

\begin{tabular}{llll}
\hline Variable & RRR & $95 \% \mathrm{Cl}$ & P-value \\
Respiratory dysfunction & & & \\
\hline IAH preoperative & & & \\
No IAH & 1 & $0.319-34.829$ & 0.315 \\
IAH & 3.333 & & \\
IAH Postoperative & & $0.555-76.175$ & 0.136 \\
No IAH & 1 & & \\
IAH & 6.500 & & \\
IAH Postop 0 hr & & $0.177-50.784$ & \\
No IAH & 1 & & - \\
IAH & 3.000 & & \\
IAH Postop 6 hrs & & & \\
No IAH & 1 & & \\
IAH & 1 & & \\
IAH Postop 24 hrs & & 1 &
\end{tabular}

IAH Postop 48 hrs

$\mathrm{NO} I \mathrm{AH}$

$\mathrm{IAH}$

Renal Dysfunction

IAH preoperatively

$\mathrm{NO}$ IAH
$\mathrm{IAH}$

1

$6.31 * 10^{8} \quad 0$

0.998

IAH Post-operatively

No IAH
IAH

IAH 0 hrs Postop

$$
\text { No IAH }
$$

$\mathrm{IAH}$

IAH 6 hrs Postop

$$
\text { No IAH }
$$

$\mathrm{IAH}$

IAH 24 hrs Postop

No IAH

IAH 48 hrs Postop

No IAH

IAH

Highlighted variables statistically significant at $p$-value $<0.05$

et al. with $49.3 \%$, this is still explained by the different study populations, and this study was carried out in the emergency ward setting compared to NICU or PICU. 
Table 5 Multivariate analysis showing IAH as a predictor of morbidity rate and mortality among adults patients scheduled and underwent Emergency laparotomy

\begin{tabular}{|c|c|c|c|}
\hline Characteristic & RRR & $95 \%$ Cl & $P$-value \\
\hline Morbidity Rate & & & \\
\hline
\end{tabular}

$\begin{array}{llll}\text { No IAH } & 1 & & \\ \text { IAH } & 1.955 & 0.844-4.529 & 0.118\end{array}$

IAH Postoperatively

NO IAH

IAH 0 hrs Postop

$$
\text { No IAH }
$$

$\mathrm{IAH}$

IAH 6 hrs Postop

\section{$\mathrm{NO} I \mathrm{AH}$}

$\mathrm{IAH}$

IAH 24 hrs Postop

$$
\text { No IAH }
$$

$\mathrm{IAH}$

$0.359-3.528$

IAH 48 hrs Postop

No IAH

Mortality Rate

IAH preoperatively

$\mathrm{NO} I \mathrm{AH}$
$\mathrm{IAH}$

IAH Postoperatively

$\mathrm{NO}$ IAH
IAH

IAH 0 hrs Postop

No IAH

IAH 6 hrs Postop

$$
\text { No IAH }
$$$$
\mathrm{IAH}
$$

IAH 24 hrs Postop

$\begin{array}{lll}\text { No IAH } & 1 \\ \text { IAH } & 3.769 & 1.113-12.760\end{array}$

IAH 48 hrs Postop

\begin{tabular}{llll} 
No IAH & 1 & & \\
IAH & 0.338 & $0.040-2.843$ & 0.318 \\
\hline
\end{tabular}

Highlighted variables statistically significant at $p$-value $<0.05$

\section{Incidence of IAH}

In the adult group, the incidence of IAH in literature varies from 2 to $81 \%$ depending on the values used to defined IAH and patient population [19, 20]. However,
Table $6 \mathrm{IAH}$ as a predictor of morbidity rate and mortality among Pediatric patients scheduled and underwent Emergency laparotomy

\begin{tabular}{llll}
\hline Characteristic & RRR & $95 \% \mathrm{Cl}$ & P-value \\
Morbidity rate & & & \\
\hline IAH preoperative & & $0.087-17.975$ & 0.870 \\
IAH & 1 & & \\
No IAH & 1.25 & $0.099-17.823$ & 0.828 \\
IAH Postoperative & & & \\
IAH & 1 & & \\
No IAH & 1.333 & & \\
IAH Postop 0 hr & & & \\
IAH & 1 & & \\
No IAH & $3.67 * 10^{8}$ & & \\
IAH Postop 6 hrs & & & 0.998 \\
IAH & 1 & & \\
No IAH & & & \\
IAH Postop 24 hrs & & & \\
IAH & $1.900^{*} 10^{8}$ & &
\end{tabular}

IAH Postop 48 hrs

$\mathrm{IAH}$

No IAH

Mortality Rate

IAH preoperative

$\begin{array}{ll}\mathrm{No} I \mathrm{AH} & 1 \\ \mathrm{IAH} & 5.39 * 10^{9}-\end{array}$

0.999

IAH Postoperative

$\mathrm{No}$ IAH

$\mathrm{IAH}$

1

13

$0.771-219.107$

0.075

IAH Post op $0 \mathrm{hr}$

$\mathrm{NO} I \mathrm{AH}$

$\mathrm{IAH}$

1

24

$1.028-560.178$

0.048

IAH Post op 6 hrs

No IAH

IAH

IAH Post op 24 hrs

$\begin{array}{ll}\mathrm{No} I \mathrm{AH} & 1 \\ \mathrm{IAH} & 7.51 * 10^{7}-\end{array}$

0.997

IAH Post op 48 hrs

No IAH 1

IAH $\quad 0.339$

$0.339 \quad 0.041-2.833$

0.318 only a few studies have reported the incidence in paediatrics, $12.6 \%$ Thabet et al. [21], and $9 \%$ Divarci et al. [14]. The incidence of IAH in our study was $20 \%$ paediatrics and $21 \%$ adults. The incidence in the adult group 
at the $0,6,24$ and $48 \mathrm{~h}$ postoperatively was $8.1,12.8,8.7$ and $8.7 \%$ respectively. At $6 \mathrm{~h}$ the incidence of IAH increases and then drop at 24 and $48 \mathrm{~h}$, this is similar to Khan et al. reported $0 \%$ at $0 \mathrm{~h}, 3.55 \%$ at $6 \mathrm{~h}$ and $0 \%$ at $24 \mathrm{~h}$ [13]. The incidence of $21 \%$ in the adults group is high therefore close attention should be paid to these patients postoperatively to avoid poor outcome. The incidence in paediatrics group at $0,6,24$ and $48 \mathrm{~h}$ was 15 , 0,5 and $0 \%$.

\section{Outcome factors associated with IAH}

In the adults group, the statistically significant outcomes associated with IAH include mortality and respiratory system dysfunction. Preoperative IAH was significantly associated with respiratory system dysfunction while post-operative IAH was significantly associated with mortality. Khan et a[13]l reported similar findings and the preoperative respiratory dysfunction is explained by the splintage of the diaphragm as the IAP progressively raises, however the after surgery respiratory function could have improved due to the decompression from surgery.

The mortality associated with IAH postoperatively at 6 and $24 \mathrm{~h}$ shows at need to objectively measure IAP in patients at risk hence early recognition and proceeds with effective intervention.

In the paediatrics group, the significant outcome associated with IAH after multivariate analysis was mortality at $0 \mathrm{~h}$, which could be explained by probable delay in surgical intervention or recognition and appropriate treatment of IAH.

\section{Limitation of the study}

The measurements may have varied depending on whether if they were taken at end of inspiration or at the end of expiration which may have led to under estimation of the readings. Sessions were conducted to train the research assistants to correctly measure the IAP.

IAP measurements were between $6 \mathrm{~h}$ interval; hence we may have missed episodes of IAH between measurements.

At IAP measured omitted at $48 \mathrm{~h}$ if pt has no episode of IAH, pre-op and post-op up to $24 \mathrm{~h}$. This was done for the concern of causing urinary tract infections in the patients, hence the reading $48 \mathrm{~h}$ was to be assumed as normal (but this was not analysed) hence our few numbers at $48 \mathrm{~h}$.

\section{Conclusion}

The prevalence and incidence of IAH in both paediatrics and adult groups in this study were high. IAH was significantly associated with mortality postoperatively and respiratory dysfunction preoperatively in the adult group but only mortality postoperatively in the paediatrics group. These conclusions add emphasis to the need to objectively monitor IAP in these patients undergoing emergency laparotomy so as to recognise and treatment IAH early.

\section{Recommendations}

Objective routine IAP measurements should be considered for all patients undergoing emergency laparotomy. Clinical protocols should be designed to guide the management of patients with IAH in the accidents and emergency surgery wards. Resources should also be channeled towards procurement of equipment required to monitor the IAP in these patients. More studies are needed to demonstrate proper guidelines on monitoring of IAP in patients undergoing emergency laparotomy.

\section{Competing interests}

All authors declare no conflict of interest.

\section{Authors' contributions}

JK, MG, OK, DN, SK, CN, DM participated in the conception, study design, data analysis and manuscript preparation. JK, CN participated in the data collection. JK,MG,SK,DM participated in the data preparation and analysis and manuscript preparation. All authors read and approved the final manuscript.

\section{Authors' information}

JK Registrar surgery (Surgical trainee) MBChB (MakCHS) MCS (ECSA) MG Associate professor MBChB, M.Med (Surgery) (MakCHS), MScHPE (Maastricht), FCSGen (ECSA).

OK Senior lecturer MBChB, M.Med (Surgery) (MakCHS), FCSGen (ECSA) DN Senior lecturer MBChB, M.Med (Surgery) (MakCHS), FCSUro (ECSA) SK Registrar surgery (Surgical trainee) MBChB (MUST)

DM Researcher MBChB (MakCHS), PHD fellow (International health) CN Nurse BSN (MakCHS)

\section{Acknowledgements}

We want to acknowledge Jovito Ojieri, Ibrahim Ssemirimo and Emmanuel Rwamutwe, who helped in data collection. Sister Janat Nawamwena and Sister Brenda Tumuhimbise for the invaluable assistance. Edwin Mwaka, Dr Moses Arinaitwe and Peter Babigumira Ahabwe for help in data management. Dr Edward Mpoza, Dr Mary Nakibirango, Hillary Turyagenda for all support and help. Friends of Kagando, Dr Peter and Liz Lunn, Kagando Hospital for the funding and extraordinary support to acquire the tools needed to carry out this research.

\section{Author details}

${ }^{1}$ Department of Surgery, College of Health Sciences, Makerere University, Mulago Hill road, P.O Box 7072, Kampala, Uganda, East Africa. ${ }^{2}$ Department of Nursing, College of Health Sciences, Makerere University, Kampala, Uganda. ${ }^{3}$ Department of Paediatrics, College of Health Sciences, Makerere University, Kampala, Uganda. ${ }^{4}$ Department of Surgery, School of Medicine, College of Health Sciences, Makerere University, P.O Box 7072 Kampala, Uganda.

Received: 26 July 2015 Accepted: 19 November 2015 Published online: 24 November 2015

\section{References}

1. Kirkpatrick AW, Roberts DJ, De Waele J, Jaeschke R, Malbrain ML, De Keulenaer B, et al. Intra-abdominal hypertension and the abdominal compartment syndrome: Updated consensus definitions and clinical practice guidelines from the World Society of the Abdominal Compartment Syndrome. Intensive Care Med. 2013;39(7):1190-206.

2. Kirkpatrick AW, Pelosi P, De Waele JJ, Malbrain ML, Ball CG, Meade MO, et al. Clinical review: Intra-abdominal hypertension: Does it influence the physiology of prone ventilation? Crit care. 2010;14(4):232. 
3. Correa-Martin L, Castellanos G, Garcia M, Sanchez-Margallo FM. Renal consequences of intraabdominal hypertension in a porcine model. Search for the choice indirect technique for intraabdominal pressure measurement. Actas Urol Esp. 2013;37(5):273-9.

4. Scollay JM, de Beaux I, Parks RW. Prospective study of intra-abdominal pressure following major elective abdominal surgery. World J Surg. 2009; 33(11):2372-7.

5. Sugrue $M$, Buhkari $Y$. Intra-abdominal pressure and abdominal compartment syndrome in acute general surgery. World J Surg. 2009;33(6):1123-7.

6. da Silva Almeida JR, Machado FS, Schettino GP, Park M, Azevedo LC Cardiopulmonary effects of matching positive end-expiratory pressure to abdominal pressure in concomitant abdominal hypertension and acute lung injury. J Trauma. 2010;69(2):375-83.

7. Moore AF, Hargest R, Martin M, Delicata RJ. Intra-abdominal hypertension and the abdominal compartment syndrome. Br J Surg. 2004;91(9):1102-10.

8. Kashtan J, Green JF, Parsons EQ, Holcroft JW. Hemodynamic effect of increased abdominal pressure. J Surg Res. 1981:30(3):249-55.

9. Carr JA. Abdominal compartment syndrome: A decade of progress. J Am Coll Surg. 2013;216(1):135-46.

10. Kimball EJ, Rollins MD, Mone MC, Hansen HJ, Baraghoshi GK, Johnston C, et al. Survey of intensive care physicians on the recognition and management of intra-abdominal hypertension and abdominal compartment syndrome. Crit Care Med. 2006;34(9):2340-8

11. Ravishankar N, Hunter J. Measurement of intra-abdominal pressure in intensive care units in the United Kingdom: A national postal questionnaire study. Br J Anaesth. 2005:94(6):763-6.

12. Malbrain ML, Chiumello D, Pelosi P, Wilmer A, Brienza N, Malcangi $V$, et al. Prevalence of intra-abdominal hypertension in critically ill patients: A multicentre epidemiological study. Intensive Care Med. 2004;30(5):822-9.

13. Khan S, Verma AK, Ahmad SM, Ahmad R. Analyzing intra-abdominal pressures and outcomes in patients undergoing emergency laparotomy. J Emerg Trauma Shock. 2010;3(4):318-25.

14. Divarci E, Karapinar B, Yalaz M, Ergun O, Celik A: Incidence and prognosis of intraabdominal hypertension and abdominal compartment syndrome in children. Journal of Pediatric Surgery 2014. doi: 10.1016/j.jpedsurg.2014.03. 014

15. Meldrum DR, Moore FA, Moore EE, Franciose RJ, Sauaia A, Burch JM. Prospective characterization and selective management of the abdominal compartment syndrome. Am J Surg. 1997;174(6):667-72. discussion 672-663.

16. Hong JJ, Cohn SM, Perez JM, Dolich MO, Brown M, McKenney MG. Prospective study of the incidence and outcome of intra-abdomina hypertension and the abdominal compartment syndrome. Br J Surg. 2002; 89(5):591-6.

17. United-Nations-Population-Division. World population prospects: The 2012 revision. New York: Population Division of the Department of Economic and Social Affairs of the United Nations Secretariat; 2013.

18. Murtaza G, Pal KM, Jajja MR, Nawaz Z, Koondhar R, Nasim S. Intra abdominal hypertension; incidence, prevalence and outcomes in a mixed intensive care unit: Prospective cohort study. Int J Surg. 2015;9:67-71.

19. Malbrain ML, Chiumello D, Cesana BM, Reintam Blaser A, Starkopf J, Sugrue $M$, et al. A systematic review and individual patient data meta-analysis on intra-abdominal hypertension in critically ill patients: The wake-up project. World initiative on Abdominal Hypertension Epidemiology, a Unifying Project (WAKE-Up!). Minerva Anestesiol. 2014;80(3):293-306.

20. Cheatham ML, Malbrain ML, Kirkpatrick A, Sugrue M, Parr M, De Waele J, et al. Results from the International Conference of Experts on Intra-abdominal Hypertension and Abdominal Compartment Syndrome. II. Recommendations. Intensive Care Med. 2007:33:951-62. 2007/03/23 edn.

21. Thabet FC, Bougmiza IM, Chehab MS, Bafaqih HA, AlMohaimeed SA, Malbrain ML: Incidence, Risk Factors, and Prognosis of Intra-Abdominal Hypertension in Critically III Children: A Prospective Epidemiological Study. Journal of intensive care medicine 2015.

\section{Submit your next manuscript to BioMed Central and we will help you at every step:}

- We accept pre-submission inquiries

- Our selector tool helps you to find the most relevant journal

- We provide round the clock customer support

- Convenient online submission

- Thorough peer review

- Inclusion in PubMed and all major indexing services

- Maximum visibility for your research 